\title{
RESEARCH AND IMPLEMENT OF QUALITY MANAGEMENT SYSTEM IN ERP
}

\author{
Yibing Li \\ Coll. Of Mech., Wuhan University of Technology, China; Email:ahlyb@tom.com
}

\begin{abstract}
Quality is crucial for the enterprise. The structure of quality management system is discussed in this paper. And the modules of function are set up under the environment of ERP. Meanwhile, this paper studies statistical process control (SPC) technology and implements the combination of SPC and ERP according to an enterprise practice. Finally, this paper gives an example to illustrate by using $\mathrm{C}++$ Builder6.0 program and SQL Server2000 database.
\end{abstract}

Key words: Enterprise Resource Planning; Quality Control; Quality Management, SPC

\section{INTRODUCTION}

Quality is crucial for the enterprise. In order to improve the quality, the enterprise must rely on not only the application of technology but also a strong quality management system. Enterprise Resources Planning (ERP) is the embodiment of the most latest and advanced enterprise management ideas. Quality management system (QMS) under the environment of ERP combines the theory of total quality management (TQM), the ideas of ISO9000, and the advantages of information integration and multi-angle data analysis. And it is a power tools for the quality continuous improvement, and is indispensable to ERP ${ }^{[1]}$.

Now, ERP system has been used in more and more enterprise. There produces a great deal of data. The new facing problem is how to make use of these data for decision ${ }^{[2]}$. This paper studies the structure of QMS and sets up the modules of function based on the enterprise's practice, and the combination of SPC technology and ERP. Finally, this paper gives an example to illustrate by using $\mathrm{C}++$ builder6.0 programs and SQL server 2000 database.

Please use the following format when citing this chapter:

Li, Yibing, 2006, in International Federation for Information Processing (IFIP), Volume 207, Knowledge Enterprise: Intelligent Strategies In Product Design, Manufacturing, and Management, eds. K. Wang, Kovacs G., Wozny M., Fang M., (Boston: Springer), pp. 570-575. 


\section{STRUCTURE AND MODULES OF QUALITY MANAGEMENT}

Setting up a valid quality management system is indispensable to the enterprise. According to the characteristic of the quality management, the quality management system has three layers ${ }^{[3,4]}$, including plan layer, administrator (control) layer and execution layer. The next layer receives the plan or control orders from the previous layer, and transmits its own control orders to the under layer and returns the feedback of the quality information to super layer. The advantage of this structure is that each layer can fully make use of its respective information and accomplish its own function. So this systematic structure of quality control has the advantage of quickly response speed, real-time control. Also it is easy to recompose and extend, and satisfy the demanding of plasticity and correctness.

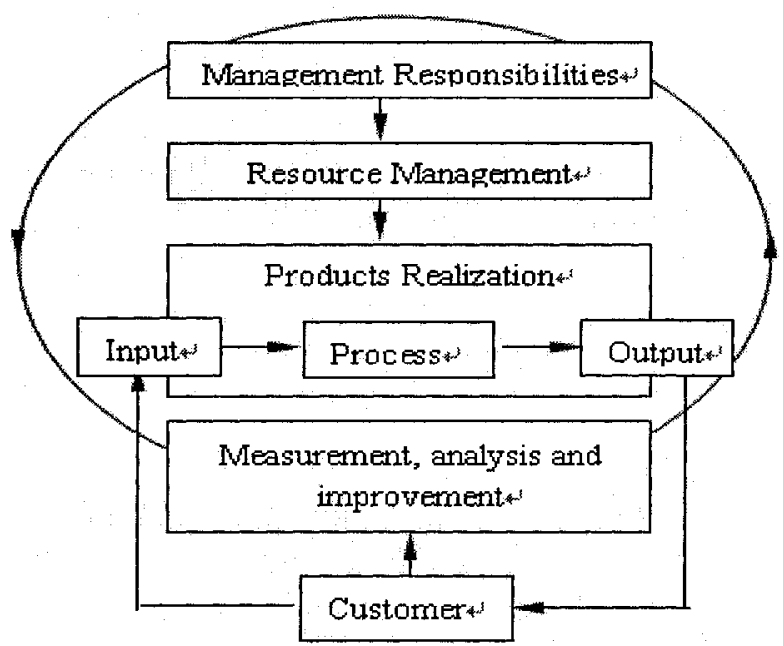

Figure I. Function of quality management

Quality management mainly includes 'management responsibilities', 'Resources management', 'products realization', 'measurement, analysis and improvement' ${ }^{[5]}$, shown as figure 1 . The main target of the system contacts outside is the customer. It reflects the basic principle of regarding customer as the centre.

According to the quality management characteristics and functions ${ }^{[6,7,8]}$, the system can compartmentalize several important modules, as shown as fig.2. This system can help the enterprises improve the dependability and quality of their products, and satisfy the demands of the customer, and realize the profits of the enterprise. 
(1) Quality standard management

The standard is a guide to acquire the best quality for the enterprise. This module manages the quality standard, the enterprise quality goal and the quality authentication, such as ISO9000 etc. So, the result of realizing standardization would be greatly improved the quality, it is also the target of all enterprise as a conscientious effort toward an end.

(2) Quality inspection and control

According to the product lifecycle quality management ideas, the main sub-modules include the inspection and control of the raw materials, semifinished product, finished product, key procedure spots and the after sale quality etc. And the main function is to collect and record all daily quality information, such as production quantities, waster quantities. And the symptom of inspection and the formative cause also must be recorded. All these are the foundation of statistic and analyses.

(3) Quality statistic and analyses

Quality statistic and analyses are important significance for increasing the economic benefits, reducing the cost, guaranteeing and improving production quality. Quality statistic and analyses are actually the data analyses, and include the fuzzy and multi-selection query and form report, the analysis of quality cost, the appraisement of provider, the management of quality advices, the disposes of quality problem etc. And the approach to analyze the quality data is the full use of statistical process control (SPC), including the data collection form, stratification, scatter, pareto, histogram, cause-effect diagram, and control chart.

(4) Quality improvement

The quality management target is the continual quality improvement. This module includes the improvement plan of customers' satisfaction, the encouraging measures of employee values' actions, quality planning, quality train and quality education, the management and selection of supply chain partnership and partners' supervising, the management of the quality control groups etc.

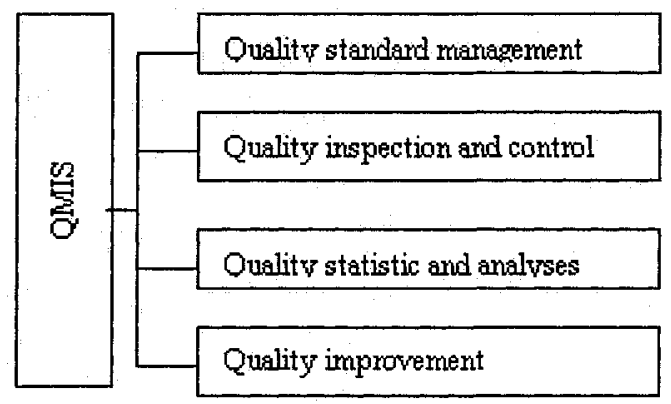

Figure 2. Modules of QMS 


\section{DESIGN AND APPLICATION OF QMS}

Quality management system is an information disposal system with computer and information technology, and can improve the quality from the point view of management and control. There is no control, no management, the opposition is right. The key of management is for valid control. So the ideas of quality management are whole participate, total control and priority of preventive measures. Now, this paper gives an example to illustrate according to an enterprise practice based on $\mathrm{C}++$ Builder6.0 program and SQL 2000 database.

(1) Data collecting and maintenance

Quality data, especially the data of key procedure is the basis of quality statistics and analyses. In generally, the approach of data acquirement includes the production record, periodical and selective examination, key procedure record etc. Of course, in the process of data collecting, the enterprise usually gives attention to two or more approaches for collecting the impersonal data. And a good software system should have convenient but powerful function. So that the user can be easy to add, delete, modify and browse the data.

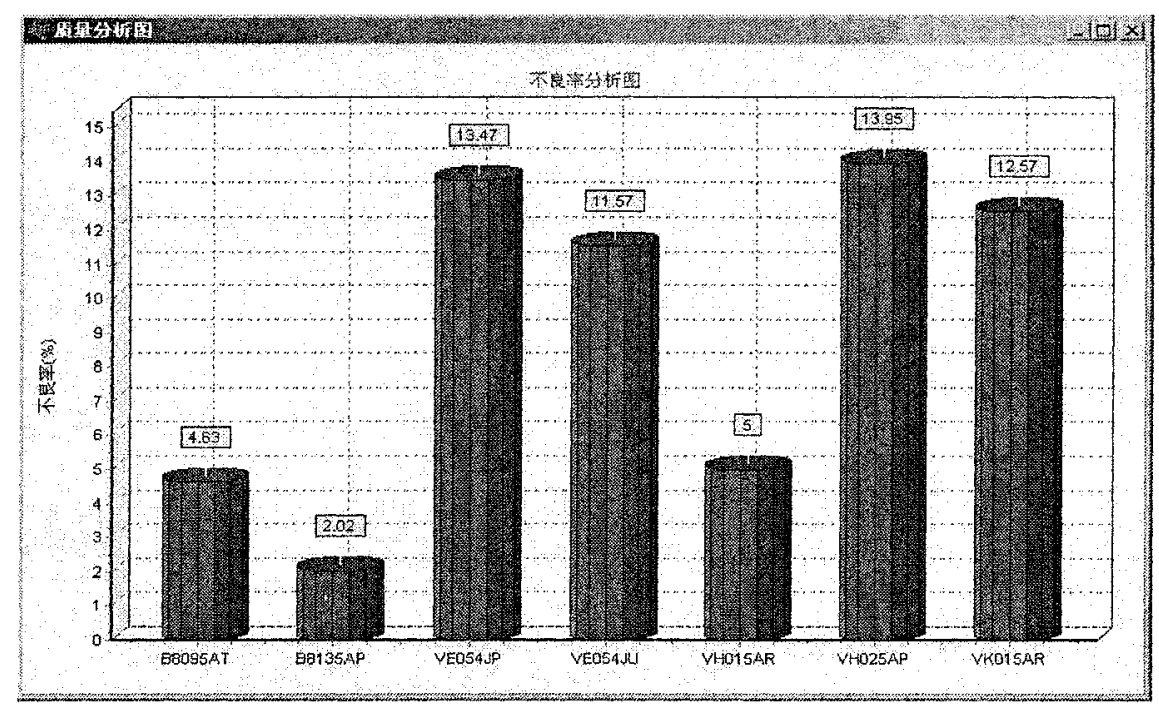

Figure 3. Histogram of ratio

(2) Quality statistics and analyses

The target of quality management is to help the manager to understand the current quality status and environment so that they can make correct decision. Because the quantities of quality data are very large, even some data are 
redundant and at random, and at the same time, different manager wants to acquire different data, the system should be able to induce and analyze these data according to the respective demands. Here, the author gives the histogram to illustrate, shown as figure 3. From this figure, it is easy to know that the high ratios of bad production are the production VHO25AP, VEO54JP, Vk015AR and WEO54JU. And the manager must be laid a strong emphasis on these productions later. And the figure4 shows the concrete symptom of the production VHO25AP daily. From this form report, it is easy to find out the quantities of every symptom, and compare the quantities of every symptom and every day each other in these period of time.

\begin{tabular}{|c|c|c|c|c|c|c|c|c|c|c|c|c|}
\hline & $2 x$ & $91 \%$ a & $10 \%=2$ & $x r=2$ & $01=2 y$ & $10 \pi-24$ & $107-26$ & $19=20$ & $07=29$ & $g r=28$ & $107-19$ & 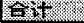 \\
\hline 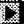 & 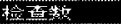 & 45902 & 32020 & 12075 & 45162 & 34457 & 27018 & 27104 & 39071 & 22411 & 20183 & 357587 \\
\hline & 不良点数 & 3074 & 2447 & 3434 & 3000 & 2276 & 2098 & 1982 & 2190 & 1122 & 1001 & 22623 \\
\hline 可 & 不良雨 & 6.7 & 7.5 & 7. 86 & 6.64 & 6.61 & 7.77 & 7.31 & 5.61 & 5.01 & 1. 96 & 6.70 \\
\hline 兹 & IC 浮起 & 2 & 3 & & 46 & & 1 & 3 & 1 & 1 & 4 & 61 \\
\hline$x$ & IC 贳品 & 1 & 1 & 1 & 3 & 3 & & 1 & 1 & & & 11 \\
\hline 筑 & IC短路 & 101 & 34 & 208 & 243 & 144 & 194 & 136 & 111 & 96 & 35 & 1392 \\
\hline 滩 & IC位移 & 3 & 12 & 12 & 8 & 18 & 23 & 4 & 6 & & 12 & 98 \\
\hline & 错件 & 1 & & 5 & 1 & 2 & 3 & & 2 & 1 & & 15 \\
\hline$x$ & 短路 & 256 & 191 & 116 & 120 & 167 & 226 & 70 & 116 & 51 & 68 & 1381 \\
\hline 4 & 二极管反贴 & 2 & $A$ & 8 & 31 & 2 & 1 & 1 & 13 & & 11 & 73 \\
\hline 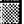 & 二极愠久品 & 69 & 9 & 26 & 26 & 63 & 26 & 5 & 3 & 5 & & 232 \\
\hline (x) & 反贴 & 4 & 8 & 11 & 18 & 7 & 1 & 17 & 10 & 1 & & 77 \\
\hline & 浮起 & 436 & 498 & 747 & 643 & 321 & 140 & 360 & 302 & 73 & 105 & 3524 \\
\hline 2x & 道件 & 92 & 115 & 90 & 102 & 82 & 86 & 126 & 111 & 21 & 25 & 850 \\
\hline 綮 & 其他 & & & & & & 1 & & & & & 1 \\
\hline & 欠品 & 379 & 321 & 390 & 368 & 234 & 312 & 204 & 142 & 165 & 153 & 2668 \\
\hline 敛 & 黨起 & 512 & 329 & 460 & 500 & 324 & 208 & 298 & 437 & 230 & 208 & 3506 \\
\hline . & 脱伴 & 6 & 23 & 26 & 59 & 30 & 7 & 12 & 9 & 18 & 1 & 191 \\
\hline 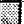 & 位移 & 947 & 830 & 1016 & 890 & 802 & 760 & 707 & 856 & 423 & 352 & 7573 \\
\hline & $F$ & 264 & 69 & 228 & 42 & 76 & 119 & 38 & 70 & 37 & 27 & 970 \\
\hline
\end{tabular}

Figure 4. Quality form report of VHO25AP

\section{(3) Quality improvement}

The aim of quality statistics and analyses based on SPC are to estimate the process under the condition of control whether or not, namely estimate the process stability. After calculating the process capability index, the manger should adjust and control the process according to the values of the process capability index so as to ensure the continual improvement. Now, the author uses the production VHO25AP to illustrate the process capability.

Here, we calculate the result: $C_{p}=1.165$. According to the judgement and disposal table of process capability, we know the process degree is secondary, and the capability of process is passable. So the continual improvement disposals include the full use of the control chart to avoid foreign fluctuation, and insisting on the sample inspection etc.

\section{CONCLUSION}

This paper gives the structure of the quality management system under the environment of ERP, and sets up the modules and describes its functions 
in detail. Meanwhile, the author tries to combine the ideas of ERP and SPC, and discuss the approach of data collecting, data analyses and process capability. Finally, the paper gives an example to illustrate according to an enterprise practice. Now, the system has been well used in this enterprise, and reached the anticipative effects.

\section{REFERENCES}

1. Luo Hong. Implementation and Design of ERP theory [M]. Beijing: Electron technology Press.2002.

2. Li Yong, Gao Jianming, Chen Fuming. The combination approach of Statistical process control and Quality System of ERP. Computer applications [J]. (2004), 12: 149 152

3. Yang $\mathrm{Xu}$, Wang Dongpeng, Ma Yulin. Study on quality management information system based on CIMS. High technology communication [J]. (2000), 8:70 75

4. Yuan Feng, Xie Liyang, Yi Gang. CIMS-oriented integrated quality management system in workshop. Computer engineering and application [J]. (2003),31:23 25

5. ISO/FDIS9001:2000Quality management system - requirement.

6. Liu Wenhui, Ma Ke, Zhao Xiaohui. Research of the quality analysis and control in manufacturing based on enterprise resources planning. Light Industry Machinery [J]. (2004), 4:155 160

7. Miao Rui, Wang Dongpeng, Yao Yingxue. The study of quality management information system for large-piece OKP based on CIMS. Computer engineering and application [J]. (2002),8:27 29

8. Kong Zaojie. Comparative research for quality information system frame model under the CIMS environment. CIMS [J]. (2000), 4:85 88

9. Wang Xueming, Guan Xiaohong, Song Guoji. Design and implementation of parts products quality control management system in MIS environment. Proceeding of 3th World Congress On Intelligent Control and Automation. June 28-July 2, 2000, HeFei, P.R.China

10.Ermer. D. S. A. Total Quality Process for design of a performance appraisal system. Transactions of Nanjing University of Aeronautics \& Astronautics. (1998),6

11. Senn J A. Info System in management. Wadsworth Publishing Company, (1987)

12.Ermer. D. S. A Total Quality Process for design of a performance appraisal system. Transactions of Nanjing University of Aeronautics \& Astronautics. (1998),6 